\title{
Inflammatory Markers in Primary Aldosteronism
}

\author{
Z. ŠOMLÓOVÁ ${ }^{1}$, O. PETRÁK ${ }^{1}$, J. ROSA $^{1}$, B. ŠTRAUCH ${ }^{1}$, T. INDRA ${ }^{1}$, T. ZELINKA ${ }^{1}$, \\ M. HALUZÍK ${ }^{1}$, V. ZIKÁN ${ }^{1}$, R. HOLAJ ${ }^{1}$, J. WIDIMSKÝ Jr. ${ }^{1}$
}

${ }^{1}$ Third Department of Internal Medicine, First Faculty of Medicine, Charles University and General University Hospital, Prague, Czech Republic

Received January 13, 2015

Accepted May 15, 2015

On-line October 8, 2015

\section{Summary}

Primary aldosteronism (PA) is the most common cause of endocrine hypertension with a high frequency of cardiovascular complications. The unfavorable cardiometabolic profile may be due to aldosterone-mediated activation of inflammatory cells, circulatory cytokines and activation of collagen synthesis in the vessel wall. Aim of our study was to evaluate differences in the levels of hsCRP, IL-6, TNF-a and N-terminal propeptide of collagen I (PINP) in patients with PA and essential hypertension (EH) as a control group, and between the subtypes of PA (aldosterone producing adenoma - APA, idiopathic hyperaldosteronism - IHA). We studied 28 patients with PA (IHA - 10 patients, APA - 12 patients, 6 unclassified) and 28 matched patients with EH. There were no differences in the levels of inflammatory markers between the followed groups [EH vs. PA: TNF-a (5.09 [3.68-6.32] vs. $4.84[3.62-6.50] \mathrm{pg} / \mathrm{ml})$, IL-6 (0.94 [0.70-1.13] vs. $0.97[0.71-$ $1.28] \mathrm{pg} / \mathrm{ml})$, hsCRP $(0.53$ [0.25-1.54] vs. 0.37 [0.31-0.61] mg/l), leukocytes $\left(6.35 \pm 1.42\right.$ vs. $\left.5.97 \pm 1.2910^{9} \mathrm{l}\right) ;$ APA vs. IHA: TNF-a (4.54 [3.62-7.03] vs. $5.19[4.23-5.27] \mathrm{pg} / \mathrm{ml}), \mathrm{IL}-6$ (0.96 [0.63$1.21]$ vs. $0.90[0.65-1.06] \mathrm{pg} / \mathrm{ml})$, hsCRP $(0.34$ [0.29-0.47] vs. $0.75[0.36-1.11] \mathrm{mg} / \mathrm{l})$, leukocytes $\quad(6.37 \pm 1.41 \quad$ vs. $\left.\left.5.71 \pm 1.2110^{9} \mathrm{I}\right)\right]$. Significant differences in the levels of PINP between PA and EH group were observed (35.18 [28.46-41.16] vs. 45.21 [36.95-62.81] $\mu \mathrm{g} / \mathrm{l}, \mathrm{p} \leq 0.003)$. No differences in inflammatory markers were observed between the followed groups, we confirmed higher levels of PINP in patients with PA.

\section{Key words}

Primary aldosteronism • TNF- $a \bullet$ IL-6 $\bullet$ hsCRP • PINP

\section{Corresponding author}

Z. Šomlóová, 3rd Department of Internal Medicine, 1st Faculty of Medicine, Charles University and General University Hospital,
U Nemocnice 2, 12808 Prague, Czech Republic. E-mail: zuzana.kratka@vfn.cz

\section{Introduction}

Primary aldosteronism (PA) characterized by autonomous overproduction of aldosterone is the most common cause of endocrine hypertension with a high frequency of cardiovascular complications. The prevalence $\mathrm{PA}$ in the non-selected hypertensive population is around $5-13 \%$ (Young 2007, Hannemann and Wallaschofski 2012) and in a preselected population of patients with severe and resistant hypertension around $20 \%$ (Calhoun et al. 2002, Šrauch et al. 2003). The main forms of PA are idiopathic aldosteronism (IHA) caused by bilateral adrenal hyperplasia and unilateral aldosterone producing adenoma (APA). Other forms of PA are less common, and include unilateral hyperplasia and rare familial aldosteronism type I, II and III. Recent data shows that patients with PA have a significantly higher rate of cardiovascular risk than patients with essential hypertension (EH) (Catena et al. 2008). There is an evidence of more frequent left ventricular hypertrophy (Rossi et al. 1996), stroke, atrial fibrillation, myocardial infarction (Milliez et al. 2005) and metabolic syndrome (Fallo et al. 2006) in patients with PA. They have also a higher urinary albumin excretion (Rossi et al. 2006), increased intima-media thickness of the common carotid artery (Holaj et al. 2007) and a higher aortic wall stiffness measured by PWV (Strauch et al. 2006). Specific treatment with adrenalectomy in patients with APA might reverse these changes (Strauch et al. 2008). The unfavorable cardio-metabolic profile in subjects with PA may account for a role of aldosterone that 
goes beyond its known hypertensive effect (Iacobellis et al. 2010). It might be due to activated inflammatory cells and circulatory cytokines (Haluzík et al. 2002, Carvajal et al. 2009, Staermose et al. 2009, Iacobellis et al. 2010) and due to activation of collagen synthesis in the vessels. It has been reported, that patients with $\mathrm{EH}$ have an increased circulating levels of immunoglobulins, autoantibodies, decreased number and altered function of T-lymphocytes (Peeters et al. 2001). An altered profile of pro- and antiinflammatory cytokines, such as TNF- $\alpha$ and IL-6, and activation of monocyte can be involved in the pathogenesis of hypertension and in changes of the arterial wall in hypertension (Peeters et al. 2001, Harrison et al. 2010). However, the effect of aldosterone overproduction on the inflammatory profile and collagen synthesis in primary aldosteronism is not clearly established. In patients with primary aldosteronism a higher level of PINP was observed but no difference in ultrasensitive CRP was found and no investigation was made to evaluate eventual subgroup differences in inflammatory markers between aldosterone producing adenoma and idiopathic hyperaldosteronism (Stehr et al. 2010). In our recent study we investigated the hypothesis, that in primary aldosteronism an immunostimulatory state is present. Because there are metabolic differences between APA and IHA (Somlóová et al. 2010) we assume, that there might be differences in inflammatory markers between aldosterone producing adenoma and idiopathic hyperaldosteronism. Aim of our study was to evaluate potential differences in the levels of hsCRP, IL-6, TNF- $\alpha$ and the N-terminal pro-peptide of collagen I, marker of collagen synthesis, in patients with PA and EH as a control group and between the most common subtypes of primary aldosteronism - APA vs. IHA.

\section{Methods}

\section{Study population}

We studied 28 patients with PA and 28 patients with EH matched by age, blood pressure, duration of hypertension and the prevalence of the metabolic syndrome. Within the group of PA we further analyzed the subgroup of 10 patients with IHA and 12 patients with APA, 6 patients remained unclassified. Subjects were recruited from consecutive patients referred to our Hypertension center in order to exclude secondary hypertension. Patients with renal failure were not included into this study, and all the patients were on a normal sodium/potassium diet with no caloric restrictions.

\section{Clinical evaluation}

To standardize the treatment and to eliminate the interferences of anti-hypertensive drugs with the reninangiotensin-aldosterone system, the previous antihypertensive therapy was withdrawn in all patients at least two weeks (in case of spironolactone at least 4 weeks) before the investigation in our center and was switched to an alpha-blocker (doxazosin) and a slow-releasing calcium channel blocker (verapamil). Patients with hypokalemia have continued with oral potassium supplementation. The suspicion of PA was based on the findings of aldosterone renin ratio (ARR) $>30 \quad(\mathrm{ng} / \mathrm{dl}) /(\mathrm{ng} / \mathrm{ml} / \mathrm{h}) \quad$ or $5.7(\mathrm{ng} / \mathrm{dl}) /(\mathrm{ng} / \mathrm{l})$ and plasma aldosterone $>15 \mathrm{ng} / \mathrm{dl}$ when measured after two-hour upright position. The diagnosis of PA was confirmed by the lack of aldosterone suppression $(<7 \mathrm{ng} / \mathrm{dl})$ following an intravenous saline load (2 1 of $0.9 \%$ saline infused over $4 \mathrm{~h}$ ). Differential diagnosis of PA forms (IHA and APA) was supported by a computed tomography scan and by a selective adrenal vein sampling (AVS). In addition, the diagnosis of APA was confirmed when successful laparoscopic adrenalectomy was associated with normalization of plasma renin activity and plasma aldosterone levels, and by histological verification. The diagnosis of IHA was based on bilateral aldosterone overproduction assessed by AVS procedure. We performed AVS without ACTH stimulation, selectivity was defined as adrenal vein/inferior vena cava cortisol gradient $>3$ and lateralization was considered to be present when the aldosterone/cortisol ratio at one side was 3 to 4-times greater than that in the contralateral vein.

\section{Laboratory methods}

All hormonal tests were performed by radioimmunoanalysis using commercially available kits in the Institutional Central Laboratory. All other biochemical parameters were analyzed using multianalyzers in the Institutional Central Laboratory. IL-6 was measured with ELISA (Human sIL-6 Instant ELISA CE-IVD, e Bioscience, Multiscan Ascent), hsCRP was measured with ELISA (Human C reactive protein Instant ELISA CEIVD, e Bioscience, Multiscan Ascent), TNF- $\alpha$ was measured with ELISA (TNF-alpha-EASIA, DIA source, Multiscan Ascent). The serum concentration of intact PINP was measured by a radioimmunoassay (Procollagen Intact PINP, Orion Diagnostica, Espoo, Finland). The within-run imprecision for the PINP was below $5 \%$, and the betweenrun imprecision was less than $7 \%$. The normal range for serum PINP is 19.3-56.4 $\mu \mathrm{g} / 1$. 
Table 1. Basic characteristics - essential hypertension vs. primary aldosteronism.

\begin{tabular}{|c|c|c|c|c|c|}
\hline & $\mathbf{n}$ & EH & n & PA & $\mathbf{p}$ \\
\hline Sex (men \%) & 15 & 52 & 15 & 54 & NS \\
\hline Age, years & 28 & $46.8 \pm 12.4$ & 28 & $49.3 \pm 8.1$ & NS \\
\hline Duration of hypertension, years & 28 & $9.0 \pm 8.7$ & 28 & $8.7 \pm 7.4$ & NS \\
\hline$B M I, \mathrm{~kg} / \mathrm{m}^{2}$ & 28 & $30.2 \pm 5.4$ & 28 & $29.9 \pm 3.1$ & NS \\
\hline Systolic BP in $24 \mathrm{~h}, \mathrm{~mm} \mathrm{Hg}$ & 28 & $141.4 \pm 11.5$ & 27 & $146.8 \pm 14.8$ & NS \\
\hline Diastolic BP in $24 \mathrm{~h}, \mathrm{~mm} \mathrm{Hg}$ & 28 & $83.6 \pm 6.9$ & 27 & $88.9 \pm 9.7$ & 0.02 \\
\hline$H R$ in $24 \mathrm{~h} \mathrm{~min}^{-1}$ & 28 & $70.8 \pm 7.2$ & 27 & $67.5 \pm 7.3$ & NS \\
\hline Serum sodium, mmol/l & 28 & $140.9 \pm 2.1$ & 28 & $143.3 \pm 2.5$ & $<0.001$ \\
\hline Serum potassium, $\mathrm{mmol} / \mathrm{l}$ & 28 & $4.2 \pm 0.4$ & 28 & $3.7 \pm 0.4$ & $<0.001$ \\
\hline Serum creatinine, $\mu \mathrm{mol} / \mathrm{l}$ & 28 & $72.1 \pm 18.1$ & 28 & $70.6 \pm 14.2$ & NS \\
\hline Glucose level, mmol/l & 28 & $5.5 \pm 1.5$ & 28 & $5.2 \pm 0.7$ & NS \\
\hline Total cholesterol, mmol/l & 28 & $5.1 \pm 1.2$ & 28 & $5.1 \pm 1.2$ & NS \\
\hline Triglycerides, mmol/l & 28 & $1.6 \pm 0.8$ & 28 & $1.3 \pm 0.8$ & NS \\
\hline HDL cholesterol, mmol/l & 28 & $1.4 \pm 0.4$ & 27 & $1.3 \pm 0.3$ & NS \\
\hline LDL cholesterol, mmol/l & 28 & $3.0 \pm 1.1$ & 27 & $3.1 \pm 1.0$ & NS \\
\hline Plasma aldosterone, $n g / l$ & 28 & $91.7(58-104.4)$ & 28 & $243.0(163.3-327.0)$ & $<0.001$ \\
\hline$P R A, \mu g / l / h$ & 25 & $0.6(0.4-1.1)$ & 24 & $0.4(0.3-0.5)$ & $<0.001$ \\
\hline$D R C, p g / m l$ & 3 & $3.8(1.7-10.7)$ & 4 & $2.5(1.7-3.3)$ & NS \\
\hline$A R R, n g / d l / / n g / m l / h$ & 25 & $11.4(5.8-22.2)$ & 24 & $66.9(42.9-101.6)$ & $<0.001$ \\
\hline$A R R, n g / d l / / n g / l$ & 2 & $2.3(1.3-3.4)$ & 4 & $28.0(8.4-55.7)$ & NS \\
\hline Basal cortisol levels, nmol/l & 28 & $566.2 \pm 149.7$ & 24 & $486.3 \pm 139.5$ & NS \\
\hline 24 h urinary cortisol levels, nmol/d & 27 & $150.4(98-200.5)$ & 26 & $149.9(119.4-226.0)$ & NS \\
\hline
\end{tabular}

EH - essential hypertension, PA - primary aldosteronism, BMI - body mass index, BP - blood pressure, HR - heart rate, PRA - plasma renin activity, DRC - direct renin concentration, ARR - aldosterone to renin ratio. Data are expressed as means \pm SD or median (interquartile range, 25th-75th percentile). P-value $<0.05$ was considered significant.

\section{Blood pressure measurement}

Clinical blood pressure (BP) values were obtained using a validated oscillometric sphygmomanometer (Dinamap, Critikon, Tampa, FL, USA). Three measurements of blood pressure were obtained in the sitting position after a five-minute rest period. Final office blood pressure was calculated as average from the second and third blood pressure readings. The 24-h ambulatory blood pressure monitoring was performed during hospitalization using an oscillometric device (SpaceLabs 90207; SpaceLabs Medical, Redmond, WA, USA).

\section{Statistical methods}

The statistical analysis was performed by STATISTICA software vers.12 (Statsoft Inc., Tulsa, OK, USA). Data are expressed depending on the normal/nonnormal distribution (Shapiro-Wilks W-test) as means \pm standard deviations or median (interquartile range, 25th- 75th percentile). Between-group comparisons were performed by two-tailed t-test for independent samples. The Kruskal-Wallis ANOVA test and Mann-Whitney U test was used for non-normally distributed variables. Pearson's correlation analysis and multiple regression analysis (stepwise forward method) were applied to assess the relationship among inflammatory markers and PINP and clinical/laboratory parameters (variables which significantly correlated in Pearson's correlation analysis entered multiple regression analysis). P-value $<0.05$ was considered significant.

\section{Results}

The basic clinical characteristics of the studied groups are shown in Table 1 and 2. Groups were matched for age, duration of hypertension, systolic blood pressure levels and the prevalence of the metabolic syndrome. We have not found in these groups any difference in the 
prevalence of glucose metabolism disorders and dyslipidemia at the time of our investigation. There were also no differences in the use of antidiabetic and hypolipidemic drugs among the studied groups.

Table 2. Basic characteristics - aldosterone producing adenoma vs. idiopathic hyperaldosteronism.

\begin{tabular}{|c|c|c|c|c|c|}
\hline & $\mathbf{n}$ & APA & $\mathbf{n}$ & IHA & $\mathbf{p}$ \\
\hline $\operatorname{Sex}(\operatorname{men} \%)$ & 6 & 50 & 6 & 60 & NS \\
\hline Age, years & 12 & $48.8 \pm 7.7$ & 10 & $49.4 \pm 8.3$ & NS \\
\hline Duration of hypertension, years & 12 & $9.1 \pm 7.2$ & 10 & $7.9 \pm 6.1$ & NS \\
\hline$B M I, \mathrm{~kg} / \mathrm{m}^{2}$ & 12 & $30.2 \pm 3.8$ & 10 & $28.9 \pm 2.5$ & NS \\
\hline Systolic BP in $24 \mathrm{~h}, \mathrm{~mm} \mathrm{Hg}$ & 12 & $146.8 \pm 16.3$ & 9 & $145.0 \pm 16.6$ & NS \\
\hline Diastolic BP in $24 \mathrm{~h}, \mathrm{~mm} \mathrm{Hg}$ & 12 & $89.1 \pm 11.5$ & 9 & $86.6 \pm 9.4$ & NS \\
\hline$H R$ in $24 h$, min $^{-1}$ & 12 & $66.3 \pm 8.3$ & 9 & $68.4 \pm 8.3$ & NS \\
\hline Serum sodium, $\mathrm{mmol} / \mathrm{l}$ & 12 & $143.6 \pm 2.8$ & 10 & $143.3 \pm 2.3$ & NS \\
\hline Serum potassium, mmol/l & 12 & $3.5 \pm 0.4$ & 10 & $3.9 \pm 0.4$ & NS \\
\hline Serum creatinine, $\mu \mathrm{mol} / \mathrm{l}$ & 12 & $67.3 \pm 14.7$ & 10 & $72.8 \pm 12.4$ & NS \\
\hline Glucose level, mmol/l & 12 & $5.2 \pm 0.5$ & 10 & $5.0 \pm 0.5$ & NS \\
\hline Total cholesterol, mmol/l & 12 & $5.1 \pm 1.2$ & 10 & $5.2 \pm 1.3$ & NS \\
\hline Triglycerides, $\mathrm{mmol} / \mathrm{l}$ & 12 & $1.2 \pm 0.9$ & 10 & $1.3 \pm 0.6$ & NS \\
\hline HDL cholesterol, $\mathrm{mmol} / \mathrm{l}$ & 12 & $1.4 \pm 0.4$ & 10 & $1.3 \pm 0.2$ & NS \\
\hline LDL cholesterol, mmol/l & 12 & $3.2 \pm 1.0$ & 10 & $3.4 \pm 1.1$ & NS \\
\hline Plasma aldosterone, $n g / l$ & 12 & $243.0(170.9-333.7)$ & 10 & $195.0(160.5-258.4)$ & NS \\
\hline$P R A, \mu g / l / h$ & 10 & $0.3(0.2-0.4)$ & 9 & $0.4(0.3-0.5)$ & NS \\
\hline$D R C, p g / m l$ & 2 & $3.3(2.5-4.1)$ & 1 & $2.4 \pm 0.0$ & NS \\
\hline$A R R, n g / d l / / n g / m l / h$ & 10 & $101.4(49.9-169.6)$ & 9 & $50.2(39.9-59.7)$ & NS \\
\hline$A R R, n g / d l / / n g / l$ & 2 & $27.8(7.8-47.8)$ & 1 & $9.1 \pm 0.0$ & NS \\
\hline Basal cortisol levels, nmol/l & 11 & $448.1 \pm 94.2$ & 8 & $615.4 \pm 114.5$ & 0.002 \\
\hline 24 h urinary cortisol levels, nmol/d & 11 & $148.7(119.4-231.0)$ & 9 & $137.4(102.0-201.2)$ & NS \\
\hline
\end{tabular}

APA - aldosterone producing adenoma, IHA - idiopathic hyperaldosteronism, BMI - body mass index, BP - blood pressure, HR - heart rate, PRA - plasma renin activity, DRC - direct renin concentration, ARR - aldosterone to renin ratio. Data are expressed as means \pm SD or median (interquartile range, 25th-75th percentile). P-value $<0.05$ was considered significant.

As expected, aldosterone levels were higher $(91.7[58.0-104.4]$ vs. $243.0[163.3-327.0] \mathrm{ng} / \mathrm{l})$ and potassium levels lower ( $4.2 \pm 0.4$ vs. $3.7 \pm 0.4 \mathrm{mmol} / \mathrm{l})$ in patients with PA, and between the two subtypes of PA, aldosterone levels were higher in patients with APA (243.0 [170.9-333.7] vs. 195.0 [160.5-258.4] ng/l). Basal cortisol levels were not statistically different between PA and EH patients but surprisingly we found significant differences in cortisol levels among patients with APA and IHA (448.1 \pm 94.2 vs. $615.4 \pm 114.5 \mathrm{nmol} / \mathrm{l})$. Patients with IHA have significantly higher basal morning cortisol levels than patients with APA (all patients were studied at the same time in the morning), but there was no difference in the levels of $24 \mathrm{~h}$ urinary cortisol (148.7 [119.4-231.0] vs. 137.4 [102.0-201.2] nmol/day) and in the cortisol levels after the short dexamethasone test (data not shown). In a subgroup analysis of patients with and without metabolic syndrome there was no difference in cortisol levels between the groups (data not shown).

The differences in inflammatory markers and PINP are summarized in Table 3 and 4 . We found no differences in the levels of inflammatory markers (TNF$\alpha$, IL-6, hsCRP) among the studied groups, but there are significant differences in the levels of PINP between PA and EH group (35.18 [28.46-41.16] vs. 45.21 [36.9562.81] $\mu \mathrm{g} / \mathrm{l})$. We have not found any gender related difference in the levels of PINP or inflammatory markers. There were no differences in the levels of $\mathrm{Ca}, \mathrm{P}$ and ALP among the groups and none of the patients had a known metastatic process in bones, therapy of osteoporosis or recent fracture. 
We found correlation between TNF- $\alpha$ levels and the prevalence of dyslipidemia, levels of HDL cholesterol and aldosterone levels, also correlation between monocytes and aldosterone and correlation between PINP and the use of statins, prevalence of hyperlipidemia and smoking but after multiple regression analysis none of them remained significant. There was no correlation between cortisol levels and inflammatory markers or PINP.

Table 3. Inflammatory markers - essential hypertension vs. primary aldosteronism.

\begin{tabular}{|c|c|c|c|c|c|}
\hline & $\mathbf{n}$ & $\mathbf{E H}$ & $\mathbf{n}$ & PA & $\mathbf{p}$ \\
\hline Leukocytes, $10^{9} / l$ & 28 & $6.35 \pm 1.42$ & 28 & $5.97 \pm 1.29$ & NS \\
\hline Neutrophils, $10^{9} / l$ & 28 & $3.56 \pm 1.2$ & 28 & $3.53 \pm 1.02$ & NS \\
\hline Lymphocytes, $10^{9} / l$ & 28 & $1.99 \pm 0.55$ & 28 & $1.77 \pm 0.46$ & NS \\
\hline Monocytes, $10^{9} / l$ & 28 & $0.54 \pm 0.16$ & 28 & $0.45 \pm 0.14$ & NS \\
\hline$h s C R P, m g / l$ & 28 & $0.53(0.25-1.54)$ & 28 & $0.37(0.31-0.61)$ & NS \\
\hline$I L-6, p g / m l$ & 27 & $0.94(0.70-1.13)$ & 28 & $0.97(0.71-1.28)$ & NS \\
\hline$T N F-\alpha, p g / m l$ & 28 & $5.09(3.68-6.32)$ & 27 & $4.84(3.62-6.50)$ & NS \\
\hline$P I N P, \mu g / l$ & 28 & $35.18(28.46-41.16)$ & 28 & $45.21(36.95-62.81)$ & 0.003 \\
\hline
\end{tabular}

EH - essential hypertension, PA - primary aldosteronism, hSCRP - high sensitivity C-reactive protein, IL-6 - interleukin 6, TNF-a tumor necrosis factor alpha, PINP - N-terminal propeptide of collagen I. Data are expressed as means \pm SD or median (interquartile range, 25th-75th percentile). P-value $<0.05$ was considered significant.

Table 4. Inflammatory markers - aldosterone producing adenoma vs. idiopathic hyperaldosteronism.

\begin{tabular}{lccccc}
\hline & $\mathbf{n}$ & APA & $\mathbf{n}$ & IHA & p \\
\hline Leukocytes, $10^{9} / l$ & 12 & $6.37 \pm 1.41$ & 10 & $5.71 \pm 1.21$ & $\mathrm{NS}$ \\
Neutrophils, $10^{9} / l$ & 12 & $3.78 \pm 0.98$ & 10 & $3.31 \pm 1.2$ & $\mathrm{NS}$ \\
Lymphocytes, $10^{9} / l$ & 12 & $1.83 \pm 0.51$ & 10 & $1.79 \pm 0.47$ & $\mathrm{NS}$ \\
Monocytes, $10^{9} / l$ & 12 & $0.47 \pm 0.14$ & 10 & $0.48 \pm 0.14$ & $\mathrm{NS}$ \\
hSCRP, $\mathrm{mg} / \mathrm{l}$ & 12 & $0.34(0.29-0.47)$ & 10 & $0.75(0.36-1.11)$ & $\mathrm{NS}$ \\
$I L-6, \mathrm{pg} / \mathrm{ml}$ & 12 & $0.96(0.63-1.21)$ & 10 & $0.90(0.65-1.06)$ & $\mathrm{NS}$ \\
$T N F-\alpha, \mathrm{pg} / \mathrm{ml}$ & 12 & $4.54(3.62-7.03)$ & 9 & $5.19(4.23-5.27)$ & $\mathrm{NS}$ \\
$P I N P, \mu \mathrm{g} / \mathrm{l}$ & 12 & $46.48(28.89-63.55)$ & 10 & $52.12(41.03-63.57)$ & $\mathrm{NS}$ \\
\hline
\end{tabular}

APA - aldosterone producing adenoma, IHA - idiopathic hyperaldosteronism, hsCRP - high sensitivity C-reactive protein, IL-6 interleukin 6, TNF-a - tumor necrosis factor alpha, PINP - N-terminal propeptide of collagen I. Data are expressed as means \pm SD or median (interquartile range, 25th-75th percentile). P-value $<0.05$ was considered significant.

\section{Discussion}

Essential hypertension is associated with higher circulating levels of inflammatory cytokines (Peeters et al. 2001, Harrison et al. 2010). Dalekos et al. (1997) recently reported increased plasma concentrations of IL-1b in patients with EH, suggesting a possible involvement of this cytokine in EH. It is quite likely that other cytokines, such as TNF- $\alpha$ and IL- 6 plays a role in the pathogenesis of hypertension by creating a cytokine milieu that promotes hypertension (Harrison et al. 2010). There is an accumulating body of evidence that alterations of the immune system are involved in the cascade of events leading to hypertension. Increased circulating levels of immunoglobulins, various types of autoantibodies, decreased numbers and altered functions of T-lymphocytes, have been reported in patients with EH (Peeters et al. 2001). Also in knockout mice with lack of $\mathrm{T}$ and $\mathrm{B}$ lymphocytes is the hypertensive response to angiotensin-II infusion very altered (Guzik et al. 2007). What is interesting is mostly no elevation of T-cells are found in blood of hypertensives and the circulating concentrations of TNF, IL-1 and IL-6 did not differ between EH patients and controls (Peeters et al. 2001, 
Harrison et al. 2010). On the other hand, circulating levels of IL-1ra are elevated in hypertensive patients. An altered profile of pro- and anti-inflammatory cytokines in $\mathrm{EH}$ can be due to monocyte activation in the circulation (Peeters et al. 2001). It is possible that the cytokine abnormalities present in hypertension are reflecting only the monocyte activation induced by endothelial damage as a direct result of mechanical stress produced by hypertension (Harrison et al. 2010).

Very little is known about the profile of proinflammatory cytokines in the circulation of patients with primary aldosteronism. It seems that aldosterone has profibrotic effects based on an immunostimulatory state (Chatzikyriakou et al. 2008). In our study we have found no differences in circulating levels of cytokines between patients with EH and PA or APA and IHA. We cannot, however, exclude the differences in local cytokines synthesis between EH and PA as plasma levels might be too robust marker to evaluate subtle local concentrations. We do not expect any differences due to medication, all patients were on doxazosin and verapamil in order not to influence the renin-angiotensin-aldosterone system.

On the other hand we confirmed, that patients with PA have higher levels of PINP, marker of collagen synthesis (Stehr et al. 2010). As presented in a couple of studies (Peeters et al. 2001, Guzik et al. 2007, Harrison et al. 2010) in hypertensive subjects the perivascular fat is overwhelmed with activated immune cells, these activated immune cells are producing different types of cytokines. Cytokines can locally activate the collagen synthesis, which may cause fibrosis of the vessel wall. It is well established that changes in extracellular matrix proteins, namely collagen and elastin content, may play a relevant role in the development of cardiovascular damage in hypertension (Rizzoni et al. 2006). Rizzoni et al. (2006) reported that a pronounced fibrosis may be detected in small arteries of patients with primary aldosteronism. Fibrosis is due to an increase in collagen and a decrease in elastin content within the tunica media (Intengan et al. 1999). The severity of fibrosis is greater than in blood-pressure-matched patients with EH but no significant correlation was observed between vascular collagen content and aldosterone levels (Rizzoni et al. 2006). Marked changes in the vessel wall, not only in small arteries, of patients with PA is confirmed also by increased aortic stiffness in these patients measured by PWV (Strauch et al. 2006). The mechanism of aldosterone-induced fibrosis of the vessel wall is still unclear, aldosterone may increase collagen I synthesis and the number of endothelin receptors (Fullerton and Funder 1994). Aldosterone has also a rapid nongenomic effect on the vessel wall mediated via activation of intracellular mineralocorticoid receptors (MR) (Funder 2006). Through MR can aldosterone directly mediate effects in target organs independent of the regulatory roles of angiotensin II (Duprez 2007) and MR receptors could be localized in endothelial and vascular smooth muscle cells (Bauersachs and Fraccarollo 2006). Extraadrenal synthesis of aldosterone in vascular wall and a localized paracrine effect may also play a role in vascular changes (Duprez 2007). Aldosterone causes reduction in vascular fibrinolysis and has profibrotic effects based on an immunostimulatory state (Chatzikyriakou et al. 2008). The profibrotic actions of aldosterone, interestingly, seem to be independent of blood pressure, since mineralocorticoid receptor inhibition with eplerenon, a selective aldosterone blocker, decreases oxidative stress, inflammation, and fibrosis in mice with chronic pressure overload in the absence of a decrease in systemic blood pressure (Díez 2007). Recent evidence shows that also angiotensin II is important in stimulating the production of reactive oxygen species and the activation of inflammatory mechanisms. Activation of the nuclear factor kappaB (NF-kappaB) stimulates the expression of genes important for expression of surface adhesion molecules and inflammation and stimulates the proliferation of lymphocytes and their activation (Luft 2001). Angiotensin II also induces endothelin-1 expression in vascular adventitial fibroblasts, stimulating collagen accumulation (An et al. 2007).

We have not found any correlation between cortisol levels and PINP or the levels of inflammatory markers. The differences in cortisol levels between APA and IHA can be due to different basic/genotype of the two conditions. In almost $40 \%$ of patients with APA a mutation in KCNJ5 gene for $\mathrm{K}^{+}$channel was found (Boulkroun et al. 2012). These tumor-causing mutations alter the channel's selectivity filter. Mutant channels gain permeability to sodium, resulting in cellular depolarization and activation of voltage-gated calcium channels. The resulting calcium influx is sufficient to produce aldosterone secretion and cell proliferation, accounting for APA development (Scholl and Lifton 2013). On the other hand in patients with idiopathic hyperaldosteronism the bilateral hyperplasia of the adrenal gland can affect not only cells of zona glomerulosa but also the cells of zona fasciculata which 
produce glucocorticoids. The difference in cortisol levels could explain partly our previous findings of different metabolic profiles of patients with APA and IHA. Patients with IHA have a higher prevalence of metabolic syndrome, higher prevalence of dyslipidemia with higher levels of triglycerides and lower levels of HDL cholesterol than patients with APA (Somlóová et al. 2012). The potential cortisol overproduction in IHA compared to APA needs further investigation and it need to be confirmed in a large number of subjects.

\section{Conclusion}

In conclusion we have shown in our study that there are no differences in circulating levels of inflammatory markers such as TNF- $\alpha$, IL-6 and hsCRP between patients with essential hypertension and patients with primary aldosteronism. It could be due to mostly local secretion of cytokines in the vessel wall. Because of the known profibrotic and proinflammatory effect of aldosterone we can presume that the measured circulating levels of inflammatory markers do not reflect the actual local levels of inflammatory markers in the arterial wall. The activation of inflammatory markers in the perivascular tissue in patients with primary aldosteronism can lead to vascular fibrosis. Our study has confirmed that patients with primary aldosteronism have higher levels of N-terminal propeptide of collagen I, marker of collagen synthesis, than patients with essential hypertension. The differences in the basal levels of cortisol between APA and IHA will need further investigation and confirmation on a bigger group of patients.

\section{Limitations}

The smaller number of patients in the subgroups of primary aldosteronism could have influenced the possible differences in plasma and serum concentration of inflammatory cytokines and also the differences in the basal cortisol levels. A possible influence of higher bone turnover on PINP levels could not be excluded because none of our patient had parathormone and D vitamin levels measured.

\section{Conflict of Interest}

There is no conflict of interest.

\section{Acknowledgements}

This work was supported by Charles University research project PRVOUK No. P35/LF1/5.

\section{References}

AN SJ, BOYD R, ZHU M, CHAPMAN A, PIMENTEL DR, WANG HD: NADPH oxidase mediates angiotensin IIinduced endothelin-1 expression in vascular adventitial fibroblasts. Cardiovasc Res 75: 702-709, 2007.

BAUERSACHS J, FRACCAROLLO D: Endothelial NO synthase target of aldosterone. Hypertension 48: $27-28,2006$. BOULKROUN S, BEUSCHLEIN F, ROSSI G-P, GOLIB-DZIB J-F, FISCHER E, AMAR L, MULATERO P, SAMSON-COUTERIE B, HAHNER S, QUINKLER M, FALLO F, LETIZIA C, ALLOLIO B, CEOLOTTO G, CICALA MV, LANG K, LEFEBVRE H, LENZINI L, MANIERO C, MONTICONE S, PERROCHEAU M, PILON C, PLOUIN P-F, RAYES N, SECCIA TM, VEGLIO F, WILLIAMS TA, ZINNAMOSCA L, MANTERO F, BENECKE A, JEUNEMAITRE X, REINCKE M, ZENNARO M-C: Prevalence, clinical, and molecular correlates of KCNJ5 mutations in primary aldosteronism. Hypertension 59: 592-598, 2012.

CALHOUN DA, NISHIZAKA MK, ZAMAN MA, THAKKAR RB, WEISSMANN P: Hyperaldosteronism among black and white subjects with resistant hypertension. Hypertension 40: 892-896, 2002.

CARVAJAL CA, HERRADA AA, CASTILlO CR, CONTRERAS FJ, STEHR CB, MOSSO LM, KALERGIS AM, FARDELLA CE: Primary aldosteronism can alter peripheral levels of transforming growth factor beta and tumor necrosis factor alpha. $J$ Endocrinol Invest 32: 759-765, 2009.

CATENA C, COLUSSI G, NADALINI E, CHIUCH A, BAROSELLI S, LAPENNA R, SECHI LA: Cardiovascular outcomes in patients with primary aldosteronism after treatment. Arch Intern Med 168: 80-85, 2008.

CHATZIKYRIAKOU S, TZIAKAS D, CHALIKIAS G, STAKOS D, THOMAIDI A, MITROUSI K, LANTZOURAKI A, KOTSIOU S, MALTEZOS E, BOUDOULAS H: Serum levels of collagen type-I degradation markers are associated with vascular stiffness in chronic heart failure patients. Eur J Heart Fail 10: 1181-1185, 2008. 
DALEKOS GN, ELISAF M, BAIRAKTARI E, TSOLAS O, SIAMOPOULOS KC: Increased serum levels of interleukin-1beta in the systemic circulation of patients with essential hypertension: additional risk factor for atherogenesis in hypertensive patients? J Lab Clin Med 129: 300-308, 1997.

DÍEZ J: Mechanisms of cardiac fibrosis in hypertension. J Clin Hypertens Greenwich Conn 9: 546-550, 2007.

DUPREZ DA: Aldosterone and the vasculature: mechanisms mediating resistant hypertension. J Clin Hypertens Greenwich Conn 9: 13-18, 2007.

FALLO F, VEGLIO F, BERTELLO C, SONINO N, DELLA MEA P, ERMANI M, RABBIA F, FEDERSPIL G, MULATERO P: Prevalence and characteristics of the metabolic syndrome in primary aldosteronism. $J$ Clin Endocrinol Metab 91: 454-459, 2006.

FULLERTON MJ, FUNDER JW: Aldosterone and cardiac fibrosis: in vitro studies. Cardiovasc Res 28: 1863-1867, 1994.

FUNDER JW: Aldosterone and the cardiovascular system: genomic and nongenomic effects. Endocrinology 147: 55645567, 2006.

GUZIK TJ, HOCH NE, BROWN KA, MCCANN LA, RAHMAN A, DIKALOV S, GORONZY J, WEYAND C, HARRISON DG: Role of the $\mathrm{T}$ cell in the genesis of angiotensin II induced hypertension and vascular dysfunction. J Exp Med 204: 2449-2460, 2007.

HALUZÍK M, SINDELKA G, WIDIMSKÝ J Jr, PRÁZNÝ M, ZELINKA T, SKRHA J: Serum leptin levels in patients with primary hyperaldosteronism before and after treatment: relationships to insulin sensitivity. J Hum Hypertens 16: 41-45, 2002.

HANNEMANN A, WALLASCHOFSKI H: Prevalence of primary aldosteronism in patient's cohorts and in population-based studies - a review of the current literature. Horm Metab Res Horm Stoffwechselforschung Horm Métabolisme 44: 157-162, 2012.

HARRISON DG, VINH A, LOB H, MADHUR MS: Role of the adaptive immune system in hypertension. Curr Opin Pharmacol 10: 203-207, 2010.

HOLAJ R, ZELINKA T, WICHTERLE D, PETRÁK O, STRAUCH B, WIDIMSKÝ J: Increased intima-media thickness of the common carotid artery in primary aldosteronism in comparison with essential hypertension. J Hypertens 25: 1451-1457, 2007.

IACOBELliS G, PETRAMALA L, COTESTA D, PERGOLINI M, ZINNAMOSCA L, CIANCI R, DE TOMA G, SCIOMER S, LETIZIA C: Adipokines and cardiometabolic profile in primary hyperaldosteronism. J Clin Endocrinol Metab 95: 2391-2398, 2010.

INTENGAN HD, DENG LY, LI JS, SCHIFFRIN EL: Mechanics and composition of human subcutaneous resistance arteries in essential hypertension. Hypertension 33: 569-574, 1999.

LUFT FC: Angiotensin, inflammation, hypertension, and cardiovascular disease. Curr Hypertens Rep 3: 61-67, 2001.

MILLIEZ P, GIRERD X, PLOUIN P, BLACHER J, SAFAR M, MOURAD J: Evidence for an increased rate of cardiovascular events in patients with primary aldosteronism. J Am Coll Cardiol 45: 1243-1248, 2005.

PEETERS AC, NETEA MG, JANSSEN MC, KULLBERG BJ, VAN DER MEER JW, THIEN T: Pro-inflammatory cytokines in patients with essential hypertension. Eur J Clin Invest 31: 31-36, 2001.

RIZZONI D, PAIARDI S, RODELLA L, PORTERI E, DE CIUCEIS C, REZZANI R, BOARI GEM, ZANI F, MICLINI M, TIBERIO GAM, GIULINI SM, ROSEI CA, BIANCHI R, ROSEI EA: Changes in extracellular matrix in subcutaneous small resistance arteries of patients with primary aldosteronism. $J$ Clin Endocrinol Metab 91: 2638-2642, 2006.

ROSSI GP, SACCHETTO A, VISENTIN P, CANALI C, GRANIERO GR, PALATINI P, PESSINA AC: Changes in left ventricular anatomy and function in hypertension and primary aldosteronism. Hypertension 27: 1039-1045, 1996.

ROSSI GP, BERNINI G, DESIDERI G, FABRIS B, FERRI C, GIACCHETTI G, LETIZIA C, MACCARIO M, MANNELLI M, MATTERELLO M-J, MONTEMURRO D, PALUMBO G, RIZZONI D, ROSSI E, PESSINA AC, MANTERO F: Renal damage in primary aldosteronism: results of the PAPY Study. Hypertension 48: 232-238, 2006.

SCHOLL UI, LIFTON RP: New insights into aldosterone-producing adenomas and hereditary aldosteronism. Curr Opin Nephrol Hypertens 22: 141-147, 2013. 
SOMLÓOVÁ Z, WIDIMSKÝ J, ROSA J, WICHTERLE D, STRAUCH B, PETRÁK O, ZELINKA T, VLKOVÁ J, MASEK M, DVORÁKOVÁ J, HOLAJ R: The prevalence of metabolic syndrome and its components in two main types of primary aldosteronism. J Hum Hypertens 24: 625-630, 2010.

SOMLÓOVÁ Z, INDRA T, ROSA J, PETRÁK O, STRAUCH B, ZELINKA T, HOLAJ R, WIDIMSKÝ J Jr: Have main types of primary aldosteronism different phenotype? Physiol Res 61: 431-436, 2012.

STAERMOSE S, MARWICK TH, GORDON RD, COWLEY D, DOWLING A, STOWASSER M: Elevated serum interleukin 6 levels in normotensive individuals with familial hyperaldosteronism type 1. Hypertension 53: e31-e32, 2009.

STEHR CB, MELLADO R, OCARANZA MP, CARVAJAL CA, MOSSO L, BECERRA E, SOLIS M, GARCÍA L, LAVANDERO S, JALIL J, FARDELLA CE: Increased levels of oxidative stress, subclinical inflammation, and myocardial fibrosis markers in primary aldosteronism patients. J Hypertens 28: 2120-2126, 2010.

ŠTRAUCH B, ZELINKA T, HAMPF M, BERNHARDT R, WIDIMSKY J: Prevalence of primary hyperaldosteronism in moderate to severe hypertension in the Central Europe region. J Hum Hypertens 17: 349-352, 2003.

STRAUCH B, PETRÁK O, WICHTERLE D, ZELINKA T, HOLAJ R, WIDIMSKÝ J: Increased arterial wall stiffness in primary aldosteronism in comparison with essential hypertension. Am J Hypertens 19: 909-914, 2006.

STRAUCH B, PETRÁK O, ZELINKA T, WICHTERLE D, HOLAJ R, KASALICKÝ M, SAFARÍK L, ROSA J, WIDIMSKÝ J Jr: Adrenalectomy improves arterial stiffness in primary aldosteronism. Am J Hypertens 21: 1086-1092, 2008.

YOUNG WF: Primary aldosteronism: renaissance of a syndrome. Clin Endocrinol (Oxf) 66: 607-618, 2007. 